\title{
Concept analysis of Perioperative Thirst for the development of a new nursing diagnosis
}

\author{
Análise de conceito da Sede Perioperatória para o desenvolvimento de um novo diagnóstico de enfermagem \\ Análisis conceptual de la Sede Perioperatoria para el desarrollo de un nuevo diagnóstico de enfermería
}

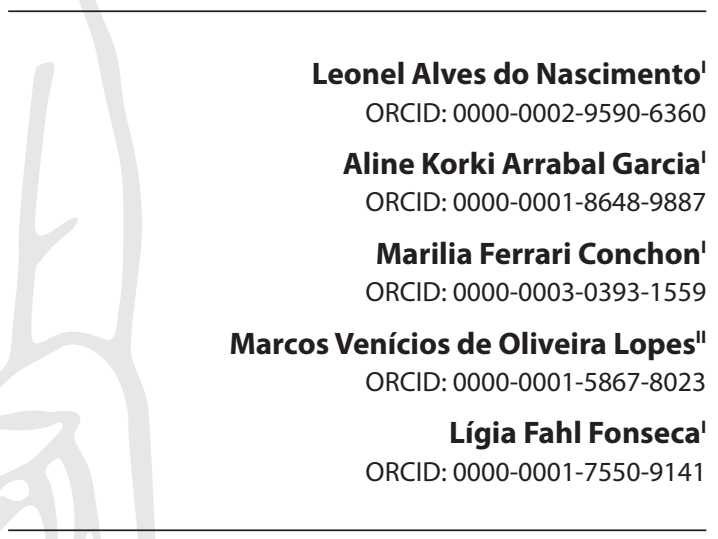

'Universidade Estadual de Londrina. Londrina, Paraná, Brazil. "Universidade Federal do Ceará. Fortaleza, Ceará, Brazil.

How to cite this article:

Nascimento LA, Garcia AKA, Conchon MF, Lopes MVO, Fonseca LF. Concept analysis of Perioperative Thirst for the development of a new nursing diagnosis. Rev Bras Enferm. 2021;74(1):e20200065. doi: http://dx.doi.org/10.1590/0034-7167-2020-0065

Corresponding author: Leonel Alves do Nascimento E-mail: leonel_lan@hotmail.com

EDITOR IN CHIEF: Dulce Barbosa ASSOCIATE EDITOR: Mitzy Reichembach

Submission: 04-14-2020

Approval: 09-13-2020

\begin{abstract}
Objectives: to analyze the perioperative thirst concept for the development of a new diagnostic structure according to NANDA International. Methods: a concept analysis study based on the framework proposed by Walker and Avant, instrumentalized through an integrative literature review based on SCOPUS, CINAHL, PUBMED, LILACS, and WOS. The elaboration of the diagnostic structure followed NANDA International guidelines. Results: 41 studies were analyzed revealing that perioperative thirst is prevalent and intense, having visceral and behavioral attributes as the core of the concept. Antecedents indicate that surgical patients are vulnerable to thirst; and consequents 16 signs and symptoms were organized and model cases were developed. A diagnostic structure has been developed for perioperative thirst. Final Considerations: concept analysis allowed language standardization that describes thirsty patients, helping the identification, planning of actions and communication of perioperative nursing care.

Descriptors: Thirst; Nursing Diagnosis; Perioperative Care; Standardized Nursing Terminology; Concept Formation.
\end{abstract}

\section{RESUMO}

Objetivos: analisar o conceito de sede perioperatória para o desenvolvimento de uma nova estrutura diagnóstica segundo a NANDA Internacional. Métodos: estudo de análise de conceito baseado no referencial proposto por Walker e Avant, instrumentalizada por meio de uma revisão integrativa da literatura nas bases SCOPUS, CINAHL, PUBMED, LILACS e WOS. A elaboração da estrutura diagnóstica seguiu as diretrizes da NANDA Internacional. Resultados: foram analisados 41 estudos revelando que a sede perioperatória é prevalente e intensa, tendo como núcleo do conceito atributos viscerais e comportamentais. Antecedentes indicam que o paciente cirúrgico é vulnerável à sede, e como consequentes, 16 sinais e sintomas foram organizados e casos modelo foram desenvolvidos. Foi desenvolvido uma estrutura diagnóstica para a sede perioperatória. Considerações Finais: a análise de conceito permitiu a padronização da linguagem que descreve o paciente com sede, auxiliando a identificação, planejamento de ações e comunicação da assistência de enfermagem perioperatória.

Descritores: Sede; Diagnóstico de Enfermagem; Assistência Perioperatória; Terminologia Padronizada em Enfermagem; Formação de Conceito.

\section{RESUMEN}

Objetivo: analizar el concepto de asiento perioperatorio para el desarrollo de una nueva estructura diagnóstica según NANDA International. Método: estudio de análisis de conceptos basado en el marco propuesto por Walker y Avant, instrumentalizado a través de una revisión integradora de la literatura basada en SCOPUS, CINAHL, PUBMED, LILACS y WOS. La elaboración de la estructura de diagnóstico siguió los lineamientos de NANDA International. Resultados: Se analizaron 41 estudios que revelaron que la sed perioperatoria es prevalente e intensa, teniendo atributos viscerales y conductuales como núcleo del concepto. Los antecedentes indican que el paciente quirúrgico es vulnerable a la sed y como consecuencia, se organizaron 16 signos y síntomas y se desarrollaron casos modelo. Se ha desarrollado una estructura de diagnóstico para el asiento perioperatorio. Consideraciones finales: el análisis de concepto permitió estandarizar el lenguaje que describe al paciente sediento, ayudando a la identificación, planificación de acciones y comunicación de los cuidados perioperatorios de enfermería.

Descriptores: Sed; Diagnóstico de Enfermería; Atención Perioperativa; Terminología Normalizada de Enfermería; Formación de Concepto. 


\section{INTRODUCTION}

Visceral stimuli, such as dry mouth, associated with motivational factors, such as the desire to drink water, Cause patients to presente thirst. As an essential physiological response for the maintenance of life, thirst begins primarily by decreasing body fluids and/or increasing blood osmolarity ${ }^{(1-3)}$.

Thirst in surgical patients has become the focus of several studies in nursing, in which a prevalence of $78 \%{ }^{(4)}$ to $89.6 \%{ }^{(5)}$ was found in adults, and also affecting children ${ }^{(6)}$ during the immediate postoperative period (IPO). It is an unpleasant symptom, of high intensity from the preoperative period until the release of the diet in the $\mathrm{IPO}^{(6-10)}$.

Nursing process supports the development of daily activities of nurses, given the continuous increase in the complexity of their clinical practice ${ }^{(11)}$. Nursing diagnosis (ND) is a relevant step in the implementation of systematic care. It is essential to incorporate perioperative thirst as ND, as it is a human response, prevalent in clinical practice, subject to intervention by nursing professionals and already reported in the scientific literature ${ }^{(10)}$. Despite this, the $11^{\text {th }}$ edition, from 2018-2020, of NANDA International does not include the description of this ND. Concept analysis is the first step in proposing a new ND, making its attributes and meanings clear and explicit ${ }^{(11-12)}$.

The International Classification for Nursing Practice (ICNP) presents the term thirst and defines it as "Perception: Feeling of desire to drink water or other liquid, referred to the mouth and throat; dry mucous membrane in the mouth and throat"(13). On the other hand, it does not describe important information for nurses' practice, such as the essential attributes of thirst, its clinical characteristics and related factors.

Surgical patients are part of a group with a high risk of developing thirst and, even with this clinical relevance, it is not yet fully and systematically addressed by associations of perioperative specialists $^{(7-8)}$. In this scenario, proposing perioperative thirst as a diagnostic label is important because it happens frequently and of high resoluteness, as the interventions for this diagnosis are relatively simple and non-invasive. Thirst may go unnoticed by nurses in their care planning if a well-defined diagnostic label is not incorporated into the profession's terminology.

There are two diagnoses present in the NANDA International taxonomy that may be related to this clinical condition, although they are different from the diagnosis of perioperative thirst. The first, called Deficient Fluid Volume (0027), is defined as intravascular, interstitial and/or intracellular fluid reduction, water loss and dehydration. This diagnosis, present in domain 2 (nutrition) and class 5 (hydration), indicates in its defining characteristics signs and symptoms of dehydration, including thirst ${ }^{(12)}$.

The second refers to the Risk for Dry Mouth (00261) diagnosis and has as its definition the susceptibility to discomfort or damage to the oral mucosa due to the reduced amount or quality of saliva to hydrate the mucosa, which can compromise health ${ }^{(12)}$. This diagnosis present in domain 11 (safety) and class 2 (physical injury) refers to the possibility of patients having dry mouth. Dehydration is one of the risk factors, in addition to some associated conditions that can be attributed to surgical patients, such as use of pharmaceutical agents, oxygen therapy and water restriction ${ }^{(12)}$.
However, although these two diagnoses have an association with perioperative thirst, none of them fully contemplates the phenomenon in question. Recent advances in the study of the functioning of the thirst mechanism have identified that thirst is not only regulated by the classic stimuli performed by homeostasis and osmolarity, but also includes anticipatory signals from oropharyngeal, gastric and water-like receptors present on the tongue. These stimuli converge to the same neurons that are activated in situations of hypovolemia and hyperosmolarity ${ }^{(14)}$. This aspect has great significance in assisting the surgical patient because, although he continuously receives intravenous fluids, it has a high prevalence and intensity of thirst, pre and postoperatively, demonstrating that the management of thirst cannot be restricted to fluid and hydroelectrolytic replacement ${ }^{(7)}$.

Since the factors that trigger thirst act concurrently and in a coordinated manner, surgical patients have characteristics that increase the risk of experiencing thirst, including the action of different medications used in this period, in addition, of course, to the intubation process, which causes oral cavity dryness due to the oropharyngeal tube permanence. The introduction of this diagnosis in the NANDA International classification will alert nurses on the risks of patients feeling thirst in the perioperative period, helping them to identify and plan actions to alleviate this discomfort.

\section{OBJECTIVES}

To analyze the perioperative thirst concept for the development of a new diagnostic structure according to NANDA International.

\section{METHODS}

Concept analysis is a careful examination of the description of a word or term whose use in the language is explained together with the elucidation of how they are associated or not with other related words or terms. The concern is in the actual and possible uses of words that convey meanings of concept $t^{(11)}$.

This concept analysis followed the methodological framework proposed by Walker and Avant ${ }^{(11)}$, which is structured in eight stages: concept selection, analysis objective, exploration of concept use, determination of attributes, construction of a model case, construction opposite case, identification of antecedents and consequences, and definition of empirical references ${ }^{(11)}$.

Determining critical attributes - one of the main points in concept analysis - consists of presenting which attributes or group of attributes are often associated with the concept, allowing a greater understanding of it, differentiating it, even, from similar or related concepts. Antecedents are events that occurred prior to the identification of the event itself, to whose occurrence they contribute. Consequences refer to a set of factors triggered as soon as the phenomenon in question is confirmed ${ }^{(11)}$.

Model cases are a real or fictional construction that best exemplify the occurrence of the concept. In this stage, three cases were built: model, borderline and opposite ${ }^{(11)}$.

The integrative review followed the five suggested steps: identification of the topic or questioning of the integrative review, sampling or search in the literature, assessment of the included 
studies, interpretation of results and synthesis of the knowledge evidenced in the articles analyzed in this review ${ }^{(15)}$.

To elaborate the research question, PICO strategy (acronym for patient, intervention, comparison, outcomes) was used ${ }^{(16)}$. The first element of the strategy, $(P)$ refers to a surgical patient, of all ages, without limitation of clinic, surgical procedure or underlying pathology; $(\mathrm{I})$ refers to the perioperative period; $(\mathrm{O})$ refers to thirst. In this study, the comparison element $(C)$ was not used. With this strategy, the following guiding question was elaborated: what is the concept, attributes, antecedents and consequences of thirst for surgical patients in the perioperative period?

Inclusion criteria stablished were and empirical research reports, qualitative and quantitative studies that answered the guiding question, available in full in Portuguese, English, and Spanish. After reading the selected articles, there was a manual search for counter-reference and inclusion of theoretical research and books that explain the physiology of thirst. Theses, dissertations, response letters and editorials were excluded from the sample, as it was considered that the articles resulting from the search would respond adequately to the guiding question. There was no limitation on the date of publication, and when the same article was found in more than one database, the article in the database with the largest number of articles was selected, excluding the repeated article from the other database.

The following controlled subjects from the Medical Subject Heading (MeSH) were adopted: thirst, postoperative period, perioperative period, preoperative period, recovery room, mouth dryness; and in the Health Sciences Descriptors (DeCS - Descritores em Ciências da Saúde) in Portuguese: sede, período pré-operatório, período pós-operatório, período perioperatório, sala de recuperação. The following uncontrolled descriptors (keywords) were used: dry mouth, salivary flow, dry lips. For the crossing of descriptors, Boolean operators (AND and OR) were used. No search filters were selected.

Article search took place on July 28, 2018, respecting the criteria and of the following databases: SCOPUS, Cumulative Index to Nursing and Allied Health Literature (CINAHL), National Library of Medicine (MEDLINE via PubMed), Latin American \& Caribbean Literature on Health Sciences (LILACS), Web of Science (WOS). Access to these databases was made through the Journal Portal of the Coordination for the Improvement of Higher Education Personnel (CAPES - Coordenação de Aperfeiçoamento de Pessoal de Nível Superior), to increase the availability of full articles.

In MEDLINE, via PubMed, the search results can be seen in Table 1.

Table 1 - Search results on MEDLINE via PubMed

\begin{tabular}{lccc}
\hline Descriptors & $\begin{array}{c}\text { Number } \\
\text { of records } \\
\text { obtained }\end{array}$ & $\begin{array}{c}\text { Selected } \\
\text { articles }\end{array}$ & $\begin{array}{c}\text { Analyzed } \\
\text { articles }\end{array}$ \\
\hline thirst AND postoperative period & 639 & 4 & 1 \\
thirst AND perioperative period & 215 & 7 & 5 \\
thirst AND preoperative period & 357 & 4 & 1 \\
thirst AND nursing, recovery room & 293 & 1 & 1 \\
thirst AND mouth dryness & 681 & 0 & 0 \\
thirst AND saliva flow & 393 & 0 & 0 \\
thirst AND dry lips & 1071 & 0 & 0 \\
Total & 3649 & 16 & 8
\end{tabular}

Studies were selected independently by two researchers who, at first, read the titles and abstracts of the studies, selecting for reading in full according to the eligibility criteria. In case of disagreement, an assessment by a third reviewer was requested.

Data were extracted using an instrument made up of items related to the identification of the study, methodological characteristics, research results, research conclusions and evidence level of the study. We sought to gather information related to the use of the concept, its meaning, which are the attributes, antecedents and consequents reported by studies regarding thirst in the perioperative period.

After this stage, it was possible to structure the organization of the ND perioperative thirst. The choice of components for the diagnostic structure was based on the findings of the review and on the researchers' knowledge of the phenomenon under study. Defining characteristics are indicators that are grouped as manifestations of a ND. The consequences in the concept analysis are transposed as defining characteristics when structuring a ND. Related factors are etiologically related to the occurrence of the diagnosis and, together with the associated conditions and populations at risk, are developed from the antecedents resulting from the concept analysis ${ }^{(11-12)}$.

Empirical references for studies of ND refer to the operational definitions developed for each related factor and defining characteristics. Although they were elaborated in this analysis, they were not presented in this study due to restrictions of size allowed for publication.

\section{RESULTS}

The sample was distributed in 19 countries, distinguished by the frequency of production: Brazil (9), United States (6), United Kingdom (3), Turkey (3), and Germany, China, Finland, Japan, Canada with two publications each. With one publication, Australia, Ethiopia, France, Kenya, India, Ireland, Sri Lanka, Sweden, Denmark and Russia.

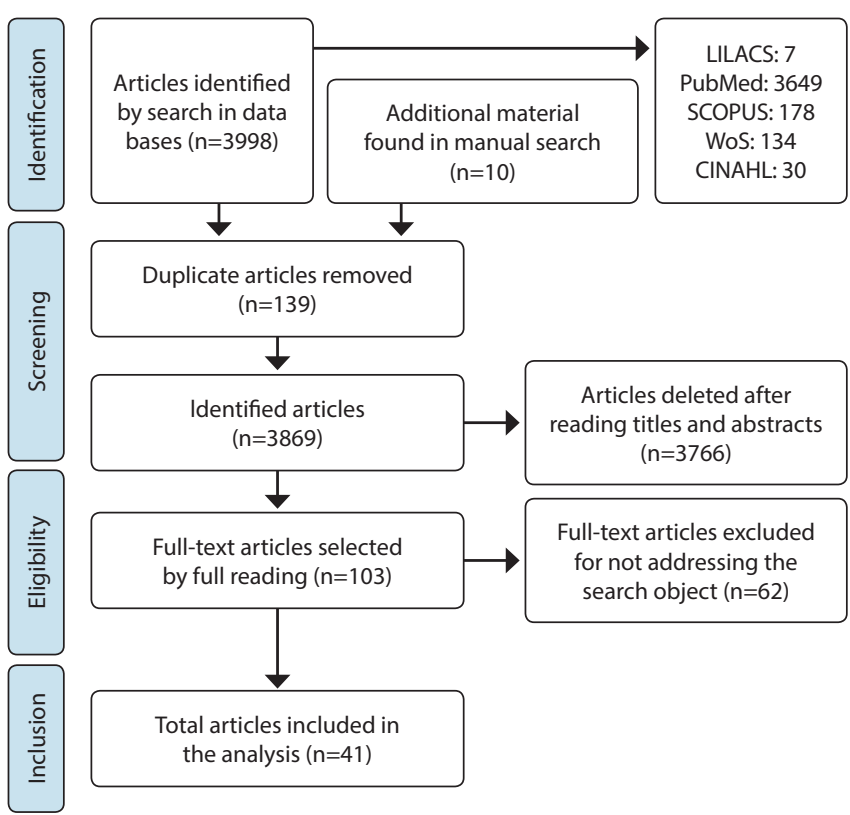

Figure 1 - Diagram of selection of articles included in this integrative review 
Among the studies assessed, non-experimental (31.7\%), experimental (26.8\%), qualitative (9.7\%) and quasi-experimental (7.3\%) designs were highlighted. The manual search for physiology studies resulted in experimental studies (9.7\%), narrative reviews of the literature (9.7\%) and a chapter in books and guidelines (4.9\%). The published articles date from 1995 to 2018. In the last five years, $68.3 \%$ of the articles included were published, demonstrating the recent interest in this theme. Articles published in English made up $85.4 \%$ of the sample. Figure 1 shows the selection flow of the included articles.

\section{Antecedents and Consequents}

Osmotic or hypovolemic factors can cause a surgical patient to have thirst. Small changes in blood osmotic concentration already activate the mechanisms that generate thirst. Changes in blood volume also activate it, but in a less sensitive way than osmolarity ${ }^{(17)}$.

The main factor is the pre and postoperative fasting time, especially when it exceeds that recommended by the scientific literature ${ }^{(6,9,18-37)}$. A similar scenario is found with pediatric patients ${ }^{(38)}$, with periods longer than recommended by international protocols $s^{(39)}$. In the surgical patient, several factors converge to stimuli the oral cavity, which are identified in the hypothalamus region, for the modulation of thirst and the release of vasopressin.

It was observed that thirst is directly linked to patients' state of discomfort in their surgical experience ${ }^{(9,22,27,37,40-44)}$. Chart 1 presents the critical attributes, antecedents and consequences related to the perioperative thirst.

Chart 1 - Critical attributes, antecedents and consequences for the perioperative thirst concept, 2019

\begin{tabular}{|c|c|}
\hline Critical attributes & Sources \\
\hline Visceral attributes & $\begin{array}{l}(5)(6)(8)(27)(35)(36) \\
(36)\end{array}$ \\
\hline Behavioral attributes & $\begin{array}{l}(2)(5)(6)(14)(36)(45) \\
(46)(47)\end{array}$ \\
\hline Antecedents & Sources \\
\hline Mouth breathing & (29) \\
\hline Dehydration & $(17)(40)$ \\
\hline Insiptus diabetes after pituitary surgery & (29) \\
\hline $\begin{array}{l}\text { Prolonged pre- and postoperative fasting } \\
\text { time }\end{array}$ & $\begin{array}{l}(5)(6)(8)(9)(18)(19) \\
(20)(21)(22)(23)(24) \\
(25)(26)(27)(28)(30) \\
(31)(32)(33)(34)(35) \\
(37)(39)\end{array}$ \\
\hline Use of opioids and anticholinergics & (5) \\
\hline Surgical patient & (36) \\
\hline Water control & (9) (41) (46) \\
\hline Dry mouth & $(1)(8)(19)(20)(28)$ \\
\hline $\begin{array}{l}\text { Insensitive loss of hydration due to the use } \\
\text { of non-humidified anesthetic gases }\end{array}$ & (40) \\
\hline $\begin{array}{l}\text { Anesthetic agents cause vasodilation and } \\
\text { induce states of relative hypovolemia }\end{array}$ & $(41)(45)$ \\
\hline Hypovolemia & (17) \\
\hline
\end{tabular}

\begin{tabular}{|c|c|}
\hline $\begin{array}{l}\text { Environmental and physical factors such as } \\
\text { heat }\end{array}$ & (6) \\
\hline Drinking water habit & (6) \\
\hline Use of nasal cap & (6) \\
\hline Intubation & (6) \\
\hline Wish to drink something refreshing & (1) \\
\hline $\begin{array}{l}\text { Changes in blood homeostasis, increased } \\
\text { osmolarity }\end{array}$ & (3) (14) (17)(45) (47) \\
\hline Anxiety & (8) \\
\hline $\begin{array}{l}\text { Drugs such as atropine, scopolamine, } \\
\text { biperiden cause dry mouth }\end{array}$ & (48) \\
\hline Rapid dehydration in children & (6) \\
\hline Consequent & Sources \\
\hline Dry mouth & (5) (6)(8) (27)(35) (36) \\
\hline Desire to drink water & (5)(36) \\
\hline Dry lips & (5) (6) (8) (36) \\
\hline Dry throat & (5) (36) \\
\hline Bad taste in the mouth & (5) (36) \\
\hline Thick tongue & (5) $(8)(36)$ \\
\hline Bitter mouth & (36) \\
\hline Rough mouth & (36) \\
\hline Irritated mouth & (36) \\
\hline Tiredness & (36) \\
\hline Friable oral cavity & (36) \\
\hline Difficulty swallowing & (36) \\
\hline Headache & (36) \\
\hline Easy bleeding from the oral cavity & (36) \\
\hline Bitter throat & (36) \\
\hline Rough throat & (36) \\
\hline Hyposalivation, thick saliva & (5) (8)(36) \\
\hline Chapped lips & (8)(36) \\
\hline Dry tongue & (36) \\
\hline Bad breath & (36) \\
\hline Dry eyes & (36) \\
\hline Loss of appetite & (36) \\
\hline Burning throat & (36) \\
\hline Burning stomach & (36) \\
\hline Drowsiness & (36) \\
\hline Dizziness & (36) \\
\hline Desire to swallow & (36) \\
\hline Xerostomia & (36) \\
\hline Crying, agitation & (6) \\
\hline $\begin{array}{l}\text { Caregiver's report is important with } \\
\text { children and patients with communication } \\
\text { difficulties }\end{array}$ & (6) \\
\hline Whitish lips & (6) \\
\hline Sore throat & (6) \\
\hline Constant swallowing of saliva & (6) \\
\hline Water search behavior & (2)(6) (14) (45) (46) (47) \\
\hline
\end{tabular}


Chart 2 - Structure of the new perioperative thirst nursing diagnosis according to NANDA-I, 2019

\begin{tabular}{|c|c|}
\hline \multicolumn{2}{|l|}{ Definition } \\
\hline \multicolumn{2}{|c|}{$\begin{array}{l}\text { Sensory, physiological and subjective experience that refers to the } \\
\text { desire to ingest water in order to restore homeostasis of body fluids, } \\
\text { generating intense discomfort when not attended. }\end{array}$} \\
\hline \multicolumn{2}{|l|}{ Defining Characteristics } \\
\hline $\begin{array}{l}\text { Dry mouth }{ }^{(5-6,8,27,35,36)} \\
\text { Constant saliva swallowing }{ }^{(6)} \\
\text { Dry throat } \\
\text { Whitish lips, }^{(5,36)} \\
{\text { Dry lips } s^{(5-6,8,36)}}_{\text {Thick tongue }^{(5,8)}} \\
\text { Halitosis }^{(36)} \\
\text { Thick saliva } \\
\end{array}$ & $\begin{array}{l}\text { Bitter mouth }^{(36)} \\
\text { Rough mouth }^{(36)} \\
\text { Friable oral cavity }^{(36)} \\
\text { Water searching } \\
\text { behavior(2,6,14,45-47) } \\
\text { Bad taste in the mouth } \\
\text { Throat burning } \\
\text { Caregive } \\
\text { Caregiver report } \\
\text { Desire to drink water }\end{array}$ \\
\hline \multicolumn{2}{|l|}{ Related Factors } \\
\hline $\begin{array}{l}\text { Prolonged pre- and postoperative } \\
\text { fasting }^{(5-6,68-9,18-28,30-35,37,39)} \\
\text { Mouth breathing } \\
\text { Increased osmolarity }{ }^{(3,14,17,45,47)} \\
\text { Dehydration } \\
\text { Insensitive loss of hydration by } \\
\text { breathing, increased by the use of } \\
\text { non-humidified anesthetic gases }{ }^{(40)}\end{array}$ & $\begin{array}{l}\text { Hypovolemia }^{(17)} \\
\text { Dry mouth }^{(1,8,19-20,28)} \\
\text { Water drinking habit }^{(6)} \\
\text { Rapid dehydration in children } \\
\text { Heat }^{(6)}\end{array}$ \\
\hline \multicolumn{2}{|l|}{ Populations at Risk } \\
\hline \multicolumn{2}{|l|}{$\begin{array}{l}\text { Age extremes } \\
\text { Need for fasting } \\
\text { Patients with diabetes mellitus }\end{array}$} \\
\hline \multicolumn{2}{|l|}{ Associated Conditions } \\
\hline $\begin{array}{l}\text { Diabetes insiptus after pituitary } \\
\text { surgery } \\
\text { Anesthetics that cause } \\
\text { vasodilation and induce states of }^{(29)} \\
\text { hypovolemia(41,45) } \\
\text { Intubation }^{(6)}\end{array}$ & $\begin{array}{l}\text { Water restriction } \\
\text { Use of muscarinic and nicotinic } \\
\text { anticholinergics } \\
\text { Nasal cap }^{(5)}\end{array}$ \\
\hline
\end{tabular}

Chart 2 demonstrates the diagnostic structure developed for Perioperative thirst based on the results of a concept analysis. In it, it is observed the inclusion of 16 possible defining characteristics and 10 related factors derived from the analysis of antecedents and consequences obtained from the concept analysis.

\section{Model case, borderline case and contrary case identification}

The following are three fictitious cases elaborated by the authors:

\section{Model case}

Amélia, 69 years old, hospitalized for hip prosthesis placement , under spinal anesthesia. On the second day of hospitalization, the preoperative fasting started at midnight and lasted until 2:00 pm on the third day of hospitalization. During the procedure, the anesthetic technique was converted to general anesthesia due to complications in spinal block. No other complications during surgery, medium bleeding. Atropine was used for extubation. Assessed in the anesthetic recovery room, she reported thirst with an intensity of eight on a 0-10 numerical visual scale. The Perioperative thirst Discomfort Scale (EDESP) ${ }^{(36)}$, was applied with a total score of 11: my mouth is dry (2), dry lips (2), tongue is thick (1), saliva is thick (1), dry throat (2), bad taste in the mouth (1) and
I feel like drinking water (2). After she was approved by the Thirst Management Safety Protocol, she received a $10 \mathrm{ml}$ ice popsicle and mentholated lip moisturizer, having her thirst relieved after the administration of two popsicle.

\section{Borderline case}

Fátima, 40 years old, on the first day of hospitalization, she underwent cholecystectomy by videolaparoscopy, under general anesthesia. In the preoperative period, he fasted liquids and solids for four hours. The procedure was performed under analgesia with morphine ( $4 \mathrm{mg} / \mathrm{EV}$ ), lasting two hours, minor intraoperative bleeding. Atropine was used for extubation. During the postanesthetic recovery, she reported having a dry mouth, but said she was not thirsty. The nurse informed her that dry mouth is a sign that patients with thirst have and that she would not need to suffer this discomfort in her recovery from surgery. It accepted the offered ice pop after passing the Thirst Safety Management Protocol. In the following assessment, the patient did not report having thirst or dry mouth.

\section{Contrary case}

Gerônimo, 53 years old, hospitalized for osteosynthesis of the right tibia, received, on the first day of hospitalization, a 30 $\mathrm{ml}$ menthol popsicle two hours before the surgical procedure. The procedure was performed under spinal anesthesia with sedation, lasting two and a half hours, minor bleeding, without complications. In the recovery room, he denied discomfort and thirst when asked. He was discharged and sent to the infirmary. The diet was released within the first hour, as he was wide awake and without nausea/vomiting.

\section{DISCUSSION}

This analysis of the perioperative thirst concept is unprecedented and necessary for strengthening perioperative nursing. Concept analysis encourages communication, as the discussion of the phenomenon, its attributes and meanings facilitate the standardization and recognition of the concept in nursing work ${ }^{(11)}$.

Thirst discomfort is frequently observed and reported in the medical literature $(25,33,37,40,42,44,49-50)$, due to high prevalence in surgical patients $^{(33,37,42,44,50)}$, affecting adults and children ${ }^{(6,24,31,44)}$, generating intense suffering ${ }^{(25,33,42,44,48)}$, stress ${ }^{(9,37,40)}$, feelings of death ${ }^{(9)}$, anxiety ${ }^{(6,25)}$, influencing the intake habits of patients and their companions ${ }^{(6)}$.

And yet, the team can ignore this symptom and tell patients that it is a common discomfort and that fasting must be maintained ${ }^{(8,37)}$. However, experiencing the discomfort of thirst has a negative impact on patient satisfaction with the surgical procedure ${ }^{(22,48)}$.

Critical attributes that comprise the core of the perioperative thirst concept include visceral and behavioral attributes. These attributes are present in all observed cases of the phenomenon and are interpreted by the organism due to interoception.

Interoception is the body's ability to perceive the internal state, bringing to consciousness physiological needs, commonly primordial functions for the maintenance of the human body. The brain areas involved to generate thirst are phylogenetically 
ancient ${ }^{(3,14,45)}$. Thirst is a complex phenomenon, caused by peripheral visceral signs, such as dry mouth ${ }^{(36)}$, neuroendocrine changes, such as increased plasma osmolarity ${ }^{(2)}$, and behavioral changes, such as desire to drink something ${ }^{(46)}$. It may or may not be linked to a physiological need for water intake initiated by habit, custom, taste, nutrition, craving for alcohol, caffeine or another drug in a drink, or a desire to ingest a drink to keep warm or cool. Much of the perception of thirst is apprehended or is a process conditioned to cultural factors or habits ${ }^{(46)}$.

Antecedents are transposed as related factors in the development of a ND. The pre and postoperative fasting time was the factor with the highest number of citations. Many hospitals remain with the "nothing after mouth after midnight" orientation in preparing the patient for the surgical procedure, even though strong evidence contraindicates this conduct. Thirst is one of the main discomforts resulting from this practice ${ }^{(18,21)}$.

Other related factors include changes in blood homeostasis. Dehydration, increased osmolarity and hypotension are present in surgical patients. The lamina terminalis, whose structure is formed by three small nuclei, subfornicalorgan (SFO), organum vasculosum of the lamina terminalis (OVLT) and mediate preopticnucleus (MnPO), detects changes in plasma osmolarity and integrate such information with other brain areas, such as the hypothalamus, responsible for vasopressin (AVP) production. This whole mechanism has the purpose of restoring the balance of cellular fluids, in circumstances of water deprivation ${ }^{(45,47)}$.

Consequences are attributes after the occurrence of the concept and, in the diagnostic structure, they represent the defining characteristics $^{(11-12)}$. Several attributes include the dryness of the oral cavity and the adjacent structures. The variety of citations resulting from this dryness demonstrate the importance that patients attach to these signs when asked about thirst.

The borderline case shows that it is common for a patient to answer that he or she does not have thirst, but that his or her mouth is dry. The team must pay attention to the fact that dry mouth is one of the main attributes presented; It is advisable, therefore, to check for the presence of other signs and consider that this patient is thirsty. It is essential to educate and guide patients about the characteristics that they may present when they are thirsty, so that they understand their discomfort and accept the available relief measures. Thirst is triggered by a neuroanatomical complex that cannot be analyzed in isolation, as it comprises visceral and motivational stimuli(46).
Considering the perioperative thirst in the light of the concept analysis enabled the organization of a diagnostic structure of this phenomenon, promoting the Systematization of Perioperative Nursing Care (SAEP - Sistematização da Assistência de Enfermagem Perioperatória).

\section{Study limitations}

A possible limitation of this research was the impossibility of including the Embase database in this review, as its access is not free.

\section{Contributions to nursing, health, and public policies}

This article promotes the understanding of perioperative thirst by the team that assists patients. Concept analysis makes it possible to include the phenomenon in training and continuing education programs for the nursing team. Language standardization facilitates the understanding of nurses in different realities, enabling the multidisciplinary team to work to alleviate this discomfort. The effort to analyze the concept is the first step to organize a diagnostic structure, expanding SAEP.

\section{FINAL CONSIDERATIONS}

The analysis of the perioperative thirst concept Allowed for the elaboration of a diagnostic structure. The critical attributes of the concept are described as visceral (dry mouth) and motivational (desire to drink water). The assessed antecedents indicate that the surgical patient is vulnerable to this diagnosis, mainly due to the specific conditions to which he is submitted as part of the surgical process. As consequences, 16 signs and symptoms could be observed as a direct result of thirst, in addition to qualitative aspects that negatively interfere in the anesthetic-surgical experience.

This study represents an advance for the literature for promoting and improving the use of diagnostic structures in nursing in perioperative care.

\section{ACKNOWLEDGMENT}

To the Study and Research Group on Thirst from The State University of Londrina for the support and knowledge exchange in relation to this important surgical discomfort.

\section{REFERENCES}

1. Kjeldsen CL, Hansen MS, Jensen K, Holm A, Haahr A, Dreyer P. Patients' experience of thirst while being conscious and mechanically ventilated in the intensive care unit. Nurs Crit Care. 2018;23(2):75-81. doi: 10.1111/nicc.12277

2. Zimmerman CA, Leib DE, Knight ZA. Neural circuits underlying thirst and fluid homeostasis. Nature Rev Neurosci. 2017;18(8):459-469. doi: $10.1038 / \mathrm{nrn} .2017 .71$

3. Stevenson RJ, Mahmut M, Rooney K. Individual differences in the interoceptive states of hunger, fullness and thirst. Appetite. 2015;95:4457. doi: 10.1016/j.appet.2015.06.008

4. Nascimento LA, Nakaya TG, Conchon MF, Garcia AKA, Pierotti I, Serato VM, et al. Prevalence, intensity and discomfort of thirst in surgical patients in the immediate post-operative period. Rev SOBECC. 2019;24(2):85-90. doi: 10.5327/Z1414-4425201900020006

5. Pierotti I, Fracarolli IFL, Fonseca LF, Aroni P, Pierotti I, Fracarolli IFL, et al. Evaluation of the intensity and discomfort of perioperative thirst. Esc Anna Nery. 2018;22(3):1-7. doi: 10.1590/2177-9465-ean-2017-0375 
6. Campana MC, Fonseca LF, Lopes DFM, Martins PR. Perceptions of caregivers about surgical children's thirst. Rev Rede Enferm Nordeste. 2015;16(6):799-808. doi: 10.15253/2175-6783.2015000600005

7. Conchon MF, Nascimento LA, Fonseca LF, Aroni P. Perioperative thirst: An analysis from the perspective of the Symptom management theory. Rev Esc Enferm USP. 2015;49(1):122-8. doi: 10.1590/S0080-623420150000100016

8. Silva LCJR, Aroni P, Fonseca LF. I am thirsty! experience of the surgical patient in the perioperative period. Rev SOBECC. 2016;21(2):75. doi: 10.5327/Z1414-4425201600020003

9. Gois CFL, Aguilar OM, Santos V, Rodríguez EOL. Stress factors for patients undergoing cardiac surgery. Invest Educ Enferm [Internet]. 2012 [cited 2019 Jul 5];30(3):312-9. Available from: http://www.scielo.org.co/pdf/iee/v30n3/v30n3a03.pdf

10. Garcia AKA, Fonseca LF, Aroni P, Galvão CM. Strategies for thirst relief: integrative literature review. Rev Bras Enferm. 2016;69(6):1215-22. doi: 10.1590/0034-7167-2016-0317

11. Walker LO, Avant KC. Strategies for theory construction in nursing.Upper Saddle River, NJ: Prentice Hall; 2011. 243 p.

12. Herdman TH, Kamitsuru S. Nursing diagnoses: definitions and classification, 2018-2020. 11th ed. New York: Thieme; 2017.512 p.

13. Garcia TR. CIPE, Classificação Internacional para a Prática de Enfermagem : versão 2017. Porto Alegre: Artmed; 2017. 264p.

14. Bichet DG. Vasopressin and the Regulation of Thirst. Ann Nutr Metab. 2018;72(2):3-7. doi: 10.1159/000488233

15. Whittemore R., Knafl, K. The integrative review: updated methodology. J Adv Nurs. 2005;52(5):546-53. doi: 10.1111/j.1365-2648.2005.03621.x

16. Galvão TF, Pereira MG. Revisões sistemáticas da literatura: passos para sua elaboração. Epidemiol Serv Saúde. 2014;23(1):183-4. doi: 10.5123/ S1679-49742014000100018

17. Hughes F, Ng SC, Mythen M, Montgomery H. Could patient-controlled thirst-driven fluid administration lead to more rapid rehydration than clinician-directed fluid management? an early feasibility study. Br J Anaesth. 2018;120(2):284-90. doi: 10.1016/j.bja.2017.11.077

18. Aguilar-Nascimento JE, Almeida DAL, Dock-Nascimento DB, Correia MITD, Campos ACL, Portari-Filho PE, et al. Actual preoperative fasting time in Brazilian hospitals: The BIGFAST multicenter study. Ther Clin Risk Manag. 2014;10(1):107-12. doi: 10.2147/TCRM.S56255

19. Jian WL, Zhang YL, Xu JM, Xia SY, Zeng H, Dai RP, et al. Effects of a carbohydrate loading on gastric emptying and fasting discomfort: An ultrasonography study.Int J Clin Exp Med. [Internet]. 2017 [cited 2019 Jul 5];10(1):788-94. Available from: http://www.ijcem.com/files/ ijcem0040776.pdf

20. Helminen H, Viitanen H, Sajanti J. Effect of preoperative intravenous carbohydrate loading on preoperative discomfort in elective surgery patients. Eur J Anaesthesiol. 2009;26(2):123-7. doi: 10.1097/eja.0b013e328319be16

21. De Jonghe B, Fajardy A, Mérian-Brosse L, Fauconnier A, Chouillard E, Debit N, et al. Reducing pre-operative fasting while preserving operating room scheduling flexibility: feasibility and impact on patient discomfort. Acta Anaesthesiol Scand. 2016;60(9):1222-9. doi: 10.1111/aas.12756

22. Bopp C, Hofer S, Klein A, Weigand MA, Martin E, Gust R. A liberal preoperative fasting regimen improves patient comfort and satisfaction with anesthesia care in day-stay minor surgery. Minerva Anestesiol [Internet]. 2011 [cited 2019 Jul 5]77(7):680-6. Available from: https:// www.minervamedica.it/en/freedownload.php?cod=R02Y2011N07A0680

23. Çakar E, Yilmaz E, Çakar E, Baydur H. The effect of preoperative oral carbohydrate solution intake on patient comfort: a randomized controlled study. J Perianesthesia Nurs. 2017;32(6):589-99. doi: 10.1016/j.jopan.2016.03.008

24. Klemetti S, Kinnunen I, Suominen T, Antila H, Vahlberg T, Grenman R, et al. The effect of preoperative fasting on postoperative thirst, hunger and oral intake in paediatric ambulatory tonsillectomy. J Clin Nurs. 2010;19(3-4):341-50. doi: 10.1111/j.1365-2702.2009.03051.x

25. Tosun B, Yava A, Açikel C. Evaluating the effects of preoperative fasting and fluid limitation. Int J Nurs Pract. 2015;21(2):156-65. doi: 10.1111/ijn.12239

26. Yildiz H, Gunal SE, Yilmaz G, Yucel S. Oral carbohydrate supplementation reduces preoperative discomfort in laparoscopic cholecystectomy. J Investig Surg. 2013;26(2):89-95. doi: 10.3109/08941939.2012.699998

27. Power S, Kavanagh DO, McConnell G, Cronin K, Corish C, Leonard M, et al. Reducing preoperative fasting in elective adult surgical patients: a case-control study. Ir J Med Sci. 2012;181(1):99-104. doi: 10.1007/s11845-011-0765-6

28. Gunawardhana Al. Knowledge, attitudes and practice of preoperative fasting guidelines in the National Hospital of Sri Lanka. Sri Lankan J Anaesthesiol. 2012;20(2):92. doi: 10.4038/slja.v20i2.4259

29. Takeuchi K, Nagatani T, Okumura E, Wakabayashi T. A novel method for managing water and electrolyte balance after transsphenoidal surgery: preliminary study of moderate water intake restriction. Nagoya J Med Sci [Internet]. 2014 [cited 2019 Jan 17];76(1-2):73-82. Available from: https://www.ncbi.nlm.nih.gov/pmc/articles/PMC4345719/

30. Engelhardt T, Wilson G, Horne L, Weiss M, Schmitz A. Are you hungry? are you thirsty?: fasting times in elective outpatient pediatric patients. Paediatr Anaesth. 2011;21(9):964-8. doi: 10.1111/j.1460-9592.2011.03573.x

31. Gebremedhn EG, Nagaratnam VB. Audit on preoperative fasting of elective surgical patients in an African academic medical center. World J Surg. 2014;38(9):2200-4. doi: 10.1007/s00268-014-2582-3

32. Imbelloni L, Gomes D, Braga R, Morais Filho G, Silva A. Clinical strategies to accelerate recovery after surgery orthopedic femur in elderly patients. Anesth Essays Res. 2014;8(2):156. doi: 10.4103/0259-1162.134490 
33. Francisco SC, Batista ST, Pena GG. Fasting in elective surgical patients: comparison among the time prescribed, performed and recommended on perioperative care protocols. ABCD Arq Bras Cir Dig. 2015;28(4):250-4. doi: 10.1590/s0102-6720201500040008

34. Njoroge G, Kivuti-Bitok L, Kimani S. Preoperative fasting among adult patients for elective surgery in a Kenyan Referral Hospital. Int Sch Res Not. 2017;2017:1-8. doi: 10.1155/2017/2159606

35. Itou K, Fukuyama T, Sasabuchi Y, Yasuda H, Suzuki N, Hinenoya H, et al. Safety and efficacy of oral rehydration therapy until $2 \mathrm{~h}$ before surgery: a multicenter randomized controlled trial. J Anesth. 2012;26(1):20-7. doi: 10.1007/s00540-011-1261-x

36. Martins PR, Fonseca LF, Rossetto EG, Martins PR, Fonseca LF, Rossetto EG. Developing and validating the Perioperative Thirst Discomfort Scale. Rev Esc Enferm USP. 2017;51(0). doi: 10.1590/s1980-220×2016029003240

37. Aroni P, Nascimento LA, Fonseca LF. Assessment strategies for the management of thirst in the post-anesthetic recovery room. Acta Paul Enferm. 2012;25(4):530-6. doi: 10.1590/S0103-21002012000400008

38. Brunet-Wood K, Simons M, Evasiuk A, Mazurak V, Dicken B, Ridley D, et al. Surgical fasting guidelines in children: are we putting them into practice? J Pediatr Surg. 2016;51(8):1298-302. doi: 10.1016/j.jpedsurg.2016.04.006

39. Practice Guidelines for Preoperative Fasting and the Use of Pharmacologic Agents to Reduce the Risk of Pulmonary Aspiration. Anesthesiology. 2017;126(3):376-93. doi: 10.1097/ALN.00000000000001452

40. Yogendran S, Asokumar B, Cheng DC, Chung F. A prospective randomized double-blinded study of the effect of intravenous fluid therapy on adverse outcomes on outpatient surgery. Anesthesia Analgesia. 1995;80:682-6. doi: 10.1097/00000539-199504000-00006

41. Ashok V, Bala I, Bharti N, Jain D, Samujh R. Effects of intraoperative liberal fluid therapy on postoperative nausea and vomiting in children: a randomized controlled trial. Paediatr Anaesth. 2017;27(8):810-5. doi: 10.1111/pan.13179

42. Puntillo KA, Arai S, Cooper B, Stotts N, Nelson J. A randosmized clinical trial of an intervention to relieve thirst and dry mouth in intensive care unit patients. Intensive Care Med. 2014;40(9):1295-302. doi: 10.1007/s00134-014-3339-z

43. Hahn R. Renal water conservation determines the increase in body weight after surgery: a randomized, controlled trial. Saudi J Anaesth. 2017;11(2):144. doi: 10.4103/1658-354X.203018

44. Perrott C, Lee CA, Griffiths S, Sury MRJ. Perioperative experiences of anesthesia reported by children and parents. Paediatr Anaesth. 2018;28(2):149-56. doi: 10.1111/pan.13300

45. Zimmerman CA, Lin Y-C, Leib DE, Guo L, Huey EL, Daly GE, et al. Thirst neurons anticipate the homeostatic consequences of eating and drinking. Nature. 2016;537(7622):680-4. doi: 10.1038/nature18950

46. Leiper JB. Thirst. In: Caballero B, Allen L, Prentice A, editors. Encyclopedia of Human Nutrition. 2nd ed. Oxford: Elsevier/Academic Press; 2005. p. 4:278.

47. Allen WE, DeNardo LA, Chen MZ, Liu CD, Loh KM, Fenno LE, et al. Thirst-associated preoptic neurons encode an aversive motivational drive. Science. 2017;357(6356):1149-55. doi: 10.1126/science.aan6747

48. Lakstygal AM, Kolesnikova TO, Khatsko SL, Zabegalov KN, Volgin AD, Demin KA, et al. DARK Classics in Chemical Neuroscience: Atropine, Scopolamine, and Other Anticholinergic Deliriant Hallucinogens. ACS Chem Neurosci. 2019;10(5):2144-2159. doi: 10.1021/ acschemneuro.8b00615

49. Bauer M, Böhrer H, Aichele G, Bach A, Martin E. Measuring patient satisfaction with anaesthesia: Perioperative questionnaire versus standardised face-to-face interview. Acta Anaesthesiol Scand. 2001;45(1):65-72. doi: 10.1034/j.1399-6576.2001.450111.x

50. Yin X, Ye L, Zhao L, Li L, Song J. Early versus delayed postoperative oral hydration after general anesthesia: A prospective randomized trial. Int J Clin Exp Med [Internet]. 2014 [cited 2018 Feb 8];7(10):3491-6. Available from: https://www.ncbi.nlm.nih.gov/pmc/articles/ PMC4238515/ 